\title{
Frequency of use of QT-interval prolonging drugs in psychiatry in Belgium
}

\author{
Eline Vandael $\cdot$ Thomas Marynissen • \\ Johan Reyntens · Isabel Spriet · Joris Vandenberghe • \\ Rik Willems $\cdot$ Veerle Foulon
}

Received: 20 December 2013/Accepted: 19 April 2014/Published online: 8 May 2014

(C) Koninklijke Nederlandse Maatschappij ter bevordering der Pharmacie 2014

\begin{abstract}
Introduction Drug-induced QT-prolongation is an established risk factor for Torsade de pointes and sudden cardiac death. The list of QT-prolonging drugs is extensive and includes many drugs commonly used in psychiatry. Aim In this study we performed a cross-sectional analysis of medication profiles to assess the prevalence of drug interactions potentially leading to QTprolongation. Setting 6 psychiatric hospitals in Flanders, Belgium. Methods For each patient, the full medication list was screened for the presence of interactions, with special attention to those with an increased risk for QT-prolongation. Current practice on QT monitoring and prevention of drug-induced arrhythmia was assessed. Main outcome measure Number of drug interactions with risk of QTprolongation. Results 592 patients (46\% female; mean age $55.7 \pm 17.1$ years) were included in the analysis. 113 QTprolonging interactions were identified in 43 patients $(7.3 \%)$. QT-prolonging interactions occurred most frequently with antidepressants $(n=102)$ and antipsychotics
\end{abstract}

E. Vandael $(\bowtie) \cdot$ I. Spriet $\cdot$ V. Foulon

Department of Pharmaceutical and Pharmacological Sciences, Clinical Pharmacology and Pharmacotherapy,

KU Leuven - University of Leuven, Herestraat 49, Box 521, 3000 Leuven, Belgium

e-mail: Eline.Vandael@pharm.kuleuven.be

T. Marynissen $\cdot$ R. Willems

Department of Cardiovascular Sciences, KU Leuven -

University of Leuven, 3000 Leuven, Belgium

T. Marynissen $\cdot$ R. Willems

Cardiology, University Hospitals Leuven,

3000 Leuven, Belgium

J. Reyntens

Sint-Jan Hospital, 9900 Eeklo, Belgium
( $\mathrm{n}=100)$. The precautions and follow-up provided by the different institutions when combining QT-prolonging drugs were very diverse. Conclusion Drug combinations that are associated with QT-prolongation are frequently used in the chronic psychiatric setting. Persistent efforts should be undertaken to provide caregivers with clear guidelines on how to use these drugs in a responsible and safe way.

Keywords Antidepressants - Antipsychotics - Belgium · Drug-induced QT-prolongation · Drug interactions ·

Psychiatry · Torsade de pointes

\section{Impact of findings on practice}

- QT-prolonging drugs (especially antidepressants and antipsychotic medication) are often combined in psychiatry, increasing the risk of QT-prolongation and Torsades de Pointes. Clear protocols for prescribing

I. Spriet

Pharmacy Department, University Hospitals Leuven,

3000 Leuven, Belgium

J. Vandenberghe

Department of Neurosciences, KU Leuven - University of

Leuven, 3000 Leuven, Belgium

J. Vandenberghe

Psychiatry, University Hospitals Leuven, 3000 Leuven, Belgium 
and follow-up of (combinations of) these drugs are needed.

- There is a need for increased awareness of the risk of QT-prolongation among healthcare professionals and for initiatives to improve the current practice.

\section{Introduction}

Worldwide more than 3 million people die annually from sudden cardiac death (SCD) [1]. In developed countries, SCD accounts for $20 \%$ of the total mortality [2-4]. Most of these cases are caused by ventricular arrhythmias (VA) [e.g. ventricular tachycardia and fibrillation (VT/VF)] [14]. Prolongation of the QT-interval is a known risk factor for Torsade de Pointes (TdP) with a possible deterioration in VT/VF leading to SCD [4-7]. Because the QT-interval is inversely related with heart rate, different correction formulae (e.g. Bazett, Fredericia) have been developed to calculate a heart rate corrected QT time (QTc) [8]. According to the expert group from the American Heart Association and the American College of Cardiology Foundation, a QTc-interval above $470 \mathrm{~ms}$ for adult males and $480 \mathrm{~ms}$ for adult females should be considered abnormal [5]. Patients with a QTc of $500 \mathrm{~ms}$ or more are considered to be at high risk for developing $\operatorname{TdP}[5,6]$.

An important risk factor for developing QT-prolongation is the use of certain drugs. The list of drugs associated with QT-prolongation is extensive [9]. Multiple drugs have been withdrawn from the market or restricted in their use because of QT-prolonging effects [6, 10, 11]. Drug interactions can further increase TdP risk, either by a pharmacodynamic (cumulative effect of two QT-prolonging drugs) or a pharmacokinetic interaction (reducing the metabolization of a QT-prolonging drug) [12].

The individual susceptibility to QT-prolongation and arrhythmia depends on multiple risk factors, of which the most important are baseline QT-prolongation, female sex, electrolyte disturbances (hypokalemia, hypomagnesaemia), bradycardia, and hereditary cardiac abnormalities (long QT syndrome, ion channel polymorphisms) [5, 6].

Psychiatric patients can be considered a population at risk for drug-induced TdP, because many antipsychotic and antidepressant agents are associated with QT-prolongation. A list of antidepressants and antipsychotics associated with QT-prolongation (in accordance with the AZCERT Classification [9]) is presented in Table 1. Both typical and atypical antipsychotics are associated with QT-prolongation and TdP [13, 14]. Leonard et al. [15] conducted a retrospective cohort study to compare the VA/SCD risk of different antipsychotic drugs. The results show that haloperidol and chlorpromazine have a higher VA/SCD risk
Table 1 AZCERT classification (version December 2013): antipsychotics and antidepressants with risk of QT-prolongation and Torsade de Pointes [9] (drugs are coded in accordance with the ATC-index of the WHO [28])

\begin{tabular}{|c|c|}
\hline Antipsychotics & Antidepressants \\
\hline \multicolumn{2}{|c|}{ List 1: Risk of Torsade de Pointes } \\
\hline Droperidol (N05AD) & Citalopram (N06AB) \\
\hline Haloperidol (N05AD) & Escitalopram (N06AB) \\
\hline \multicolumn{2}{|l|}{ Pimozide (N05AG) } \\
\hline \multicolumn{2}{|c|}{ Chlorpromazine (N05AA) ${ }^{\mathrm{a}}$} \\
\hline \multicolumn{2}{|l|}{ Mesoridazine (N05AA) ${ }^{a}$} \\
\hline \multicolumn{2}{|l|}{ Sulpiride (N05AL) } \\
\hline \multicolumn{2}{|l|}{ Thioridazine (N05AA) ${ }^{\mathrm{a}}$} \\
\hline \multicolumn{2}{|c|}{ List 2: Possible risk of Torsade de Pointes } \\
\hline Clozapine (N05AH) & Lithium (N05AN) \\
\hline \multicolumn{2}{|l|}{ Olanzapine (N05AH) } \\
\hline Paliperidon (N05AX) & Mirtazapine (N06AX) \\
\hline Quetiapine (N05AH) & Venlafaxine (N06AX) \\
\hline \multicolumn{2}{|l|}{ Risperidone (N05AX) } \\
\hline \multicolumn{2}{|l|}{ Sertindol (N05AE) } \\
\hline \multicolumn{2}{|l|}{ Iloperidone $(\mathrm{N} 05 \mathrm{AX})^{\mathrm{a}}$} \\
\hline \multicolumn{2}{|l|}{ Ziprasidone (N05AE) ${ }^{\mathrm{a}}$} \\
\hline \multicolumn{2}{|c|}{ List 3: Conditional risk of Torsade de Pointes } \\
\hline \multirow[t]{12}{*}{ Amisulpride (N05AL) } & Amitriptyline (N06AA) \\
\hline & Clomipramine (N06AA) \\
\hline & Desipramine (N06AA) ${ }^{\mathrm{a}}$ \\
\hline & Doxepine (N06AA) \\
\hline & Fluoxetine (N06AB) \\
\hline & Imipramine (N06AA) \\
\hline & Nortriptyline (N06AA) \\
\hline & Paroxetine (N06AB) \\
\hline & Protriptyline (N06AA) ${ }^{\mathrm{a}}$ \\
\hline & Sertraline (N06AB) \\
\hline & Trazodone (N06AX) \\
\hline & Trimipramine (N06AA) ${ }^{a}$ \\
\hline
\end{tabular}

Risk of $T d P$ substantial evidence supports the conclusion that these drugs prolong QT intervals and have a risk of TdP when used as directed in labeling. Possible risk of TdP substantial evidence supports the conclusion that these drugs can cause QT-prolongation but there is insufficient evidence that the drugs, when used as directed in labeling, have a risk of causing TdP. Conditional risk of TdP substantial evidence supports the conclusion that these drugs prolong QT and have a risk of developing TdP but only under certain known conditions

${ }^{\text {a }}$ Not on the market in Belgium

than olanzapine, risperidone a similar risk and quetiapine a $30 \%$ lower risk than olanzapine. Among antidepressants, there is more uncertainty. Several case reports have linked 'selective serotonin reuptake inhibitors' (SSRI) with QTprolongation, but other evidence is limited. Citalopram and escitalopram appear more likely than others to prolong the 
QT-interval. Tricyclic antidepressants are also associated with QT-prolongation, especially amitriptyline [16, 17]. However, a cohort study of Leonard et al. [18] did not found significant differences in VA/SCD risk between paroxetine and 11 other antidepressants. Only mirtazapine had a significant higher risk of VA/SCD than paroxetine, but the authors suggest that this could be due to confounding factors.

The increased risk of QT-prolongation in psychiatric patients is also due to the use of combinations of psychotropic drugs [19]. In a German study of Seemuller et al. [20], $45 \%$ of 1,014 depressed inpatients received a comedication with an antipsychotic drug. Moreover, data of the German drug surveillance system [Arzneimittelsicherheit in der Psychiatrie (AMSP), 1994-2009] suggest that the use of comedication is increasing [21]. Data of a National Audit of Schizophrenia (NAS) in England and Wales, involving 5,055 schizophrenia outpatients, revealed that antipsychotic polypharmacy occurred in $15.9 \%$ of the patients [22]. Combinations of psychotropic drugs can lead to additive effects on the QT-interval. Sala et al. [23] found a significant QT-prolongation following the combination of an antipsychotic with an antidepressant agent, while monotherapy with the antipsychotic agent did not significant prolonged the QT-interval.

Guidelines to help clinicians to deal with the risk of QTprolongation are available. In a guideline of 2010, the American College of Cardiology Foundation and the American Heart Association [5] recommend an electrocardiogram (ECG) before and 8-12 $\mathrm{h}$ after the start, after raising the dose or with an overdose of a QT-prolonging drug. They speculate that action (changing therapy, checking for drug interactions, bradycardia or electrolyte disturbances) is necessary when the QTc-interval is above $500 \mathrm{~ms}$ or the delta QTc is above $60 \mathrm{~ms}$. In a consensus statement of 2005, the Royale College of Psychiatrists in London [24] also advise an ECG before and during the therapy with psychotropic drugs, especially with high doses, parenteral use, psychotropic drugs with a high risk of TdP and in patients with a history of cardiovascular disease. The consensus statement of 2002 by the Cardiac Safety in Schizophrenia Group [25] stated that individual risk factors for QT-prolongation and TdP should be verified and when necessary, the patient should be referred to a cardiologist.

Few studies have investigated the prevalence of QTprolongation in psychiatry [26, 27]. In addition, these studies had no attention for drug interactions with risk of QT-prolongation. Therefore, there is only limited evidence on the prevalence of QT-prolonging drug interactions. Moreover, data is lacking on current practice in handling drug interactions with risk of QT-prolongation (in psychiatry and in general).

\section{Aim of the study}

The aim of this study was to analyze the extent to which antipsychotics and antidepressants with risk of QT-prolongation are combined in psychiatry and to assess the safety measures that are used to follow-up the risk of QTprolongation and TdP in this setting.

\section{Ethical approval}

The study protocol was approved by the ethics committees from the University Hospitals Leuven and from the different psychiatric institutions.

\section{Methods}

We used a cross-sectional design to answer our research question. In May 2008, a total of 600 patients were included from a convenient sample of 6 psychiatric hospitals in Flanders, Belgium (Sint-Jan hospital, Eeklo (201 beds); Sint-Jan-Baptist hospital, Zelzate (250 beds); Zoete Nood Gods hospital, Lede (191 beds); Sint-Alexius hospital, Grimbergen (171 beds); Sint-Lucia and Sint-Hieronymus hospitals, St-Niklaas (respectively 290 and 220 beds). In each hospital, 100 patients were randomly selected out of all current inpatients stratified by wards (similar in the six psychiatric institutions). During dataanalysis, 8 patients were excluded because of incomplete data. An independent Student's $t$ test was used to compare the mean age between genders.

Anonymous demographic data were collected. For each patient, the full medication list (at the time of inclusion) was screened for the presence of interactions using the online tool DelphiCare (available through http://delphicare. apb.be). The DelphiCare drug database is developed by the Centre for Pharmaceutical Information (CFI) from the Belgian Pharmaceutical Association. In addition to information on formulation, dosage, side-effects, and (contra) indications of all drugs used in Belgium, this database also provides detailed information on drug interactions. The part about drug interactions is based on the ABDATAdatabase (ABDATA Pharma-Daten-Service, http://www. wuv-gmbh.de). DelphiCare was selected for the screening of interactions, because in Belgium it is often integrated in medical and pharmaceutical software used for prescribing and delivering drugs (as was the case in 4 of the 6 participating psychiatric institutions), where it can generate automatic alerts when a drug is added which could possibly cause interactions.

The drugs involved in the drug interactions with risk of QT-prolongation identified by DelphiCare (version 2008), 
were compared with the AZCERT classification (version December 2013) [9].

A non-parametric test (Mann-Whitney U test, $5 \%$ significance level) was used to compare the average number of drug interactions per patient profile between the hospitals where DelphiCare was integrated in the medical and pharmaceutical software and hospitals without a drug interaction checker integrated in the software.

The drugs and drug classes involved in the QT-prolonging interactions were summarized and coded in accordance with the ATC-index of the World Health Organization (WHO) [28]. Furthermore the precautions and follow-up provided by the different institutions were assessed. To that purpose, five drug interactions were randomly selected in each participating hospital, involving 23 patients. For these 23 patients, the pharmacists were asked to fill out a Case Report Form to check for available safety measures (ECGs, lab results, evaluation of other risk factors of the patient). There was also a discussion with the responsible pharmacist and treating physician.

Data analysis was performed using Microsoft Excel, Graphpad Prism 5 and SPSS 20 for windows. Data are presented as mean $\pm \mathrm{SD}$ or median \pm interquartile range (IQR) when appropriate.

\section{Results}

\section{Patient characteristics}

The medication profiles of 592 patients were included in the analysis, equally divided among the participating institutions (see Table 2). There were 273 females (46\%) (mean age $55.7 \pm 17.1$ years) and 319 males (54\%) (mean age $49.5 \pm 17.0$ years) with an overall mean age of $52.4 \pm 17.3$ years (significant difference between the mean age of males and females $(p<0.001))$. The median duration of hospital stay at the time of data collection was 166 days (IQR 61-526).

\section{Drug interactions}

Screening of the medication profiles with DelphiCare identified a total of 965 interactions in 360 patients $(60.8 \%)$, of which 593 were graded as severe $(61.5 \%)$ and 21 as very severe $(2.2 \%)$ in DelphiCare. Table 2 gives an overview of the number of interactions in each psychiatric institution. There was no significant difference in the average number of drug interactions per patient between hospitals where DelphiCare was integrated in the software and hospitals without a drug interaction checker $(p=0.643)$.

One hundred thirteen of the 965 interactions $(11.7 \%)$ carried a risk for QT-prolongation (classified as severe or
Table 2 Overview of the number of interactions in the different psychiatric institutions

\begin{tabular}{lclll}
\hline & $\begin{array}{l}\text { Total } \\
\text { number } \\
\text { of patients }\end{array}$ & $\begin{array}{l}\text { Number of } \\
\text { patients with } \\
\text { at least one } \\
\text { drug } \\
\text { interaction (\%) }\end{array}$ & $\begin{array}{l}\text { Total } \\
\text { number } \\
\text { of drug } \\
\text { interactions }\end{array}$ & $\begin{array}{l}\text { Average } \\
\text { number } \\
\text { of drug } \\
\text { interactions } \\
\text { per patient }\end{array}$ \\
\hline Hospital A & 88 & $61(69.3)$ & 162 & 1.84 \\
Hospital B $^{\mathrm{a}}$ & 96 & $55(57.3)$ & 153 & 1.59 \\
Hospital C $^{\mathrm{a}}$ & 92 & $52(56.5)$ & 153 & 1.66 \\
Hospital D $^{\mathrm{a}}$ & 96 & $78(81.3)$ & 234 & 2.44 \\
Hospital E & 121 & $73(60.3)$ & 185 & 1.53 \\
Hospital F & 99 & $41(41.4)$ & 153 & 1.55 \\
Total & 592 & $360(60.8)$ & 965 & 1.63 \\
\hline
\end{tabular}

a DelphiCare is integrated in the medical and pharmaceutical software used for prescribing and delivering drugs

very severe) and were found in 43 patients $(7.3 \%)$ of which $53.5 \%$ were men. The median duration of hospital stay for these 43 patients was 117 days (IQR 62-521). Of these patients, $39.5 \%$ resided in an acute care facility (median hospital stay 72 days, IQR 41-108); the others in a chronic care facility (median hospital stay 378 days, IQR 93-657).

The drug classes involved in QT-prolonging interactions are displayed in Fig. 1. QT-prolonging interactions occurred most frequently with antidepressants $(\mathrm{n}=102$, $90.27 \%$ of cases $)$ and antipsychotics $(n=100,88.50 \%$ of cases). In Table 3, the antidepressants and antipsychotics that were most involved in these interactions are listed. Table 4 shows the different combinations that occurred the most.

The results of the comparison of the drugs that were involved in the drug interactions with risk of QT-prolongation identified by DelphiCare with the QT-drug lists of AZCERT [9], are displayed in Table 5. More than $50 \%$ of the drugs that were involved in these drug interactions are classified in list 1 or list 2 of AZCERT. However, $19.9 \%$ of the drugs were not classified in the QT-drug lists.

\section{Safety measures}

The precautions and follow-up provided by the different institutions when starting a QT-prolonging drug were very diverse. In 4 of the 6 institutions, a blood analysis and an ECG were performed systematically on admission. In 1 hospital, an ECG was only performed at the start of a QTprolonging drug. In the last hospital, ECG and blood analysis were rarely performed.

In none of the six institutions, a follow-up ECG was performed after starting a QT-prolonging drug if the baseline ECG was normal. In one hospital, ECG registration was repeated on a yearly basis, regardless of changes 


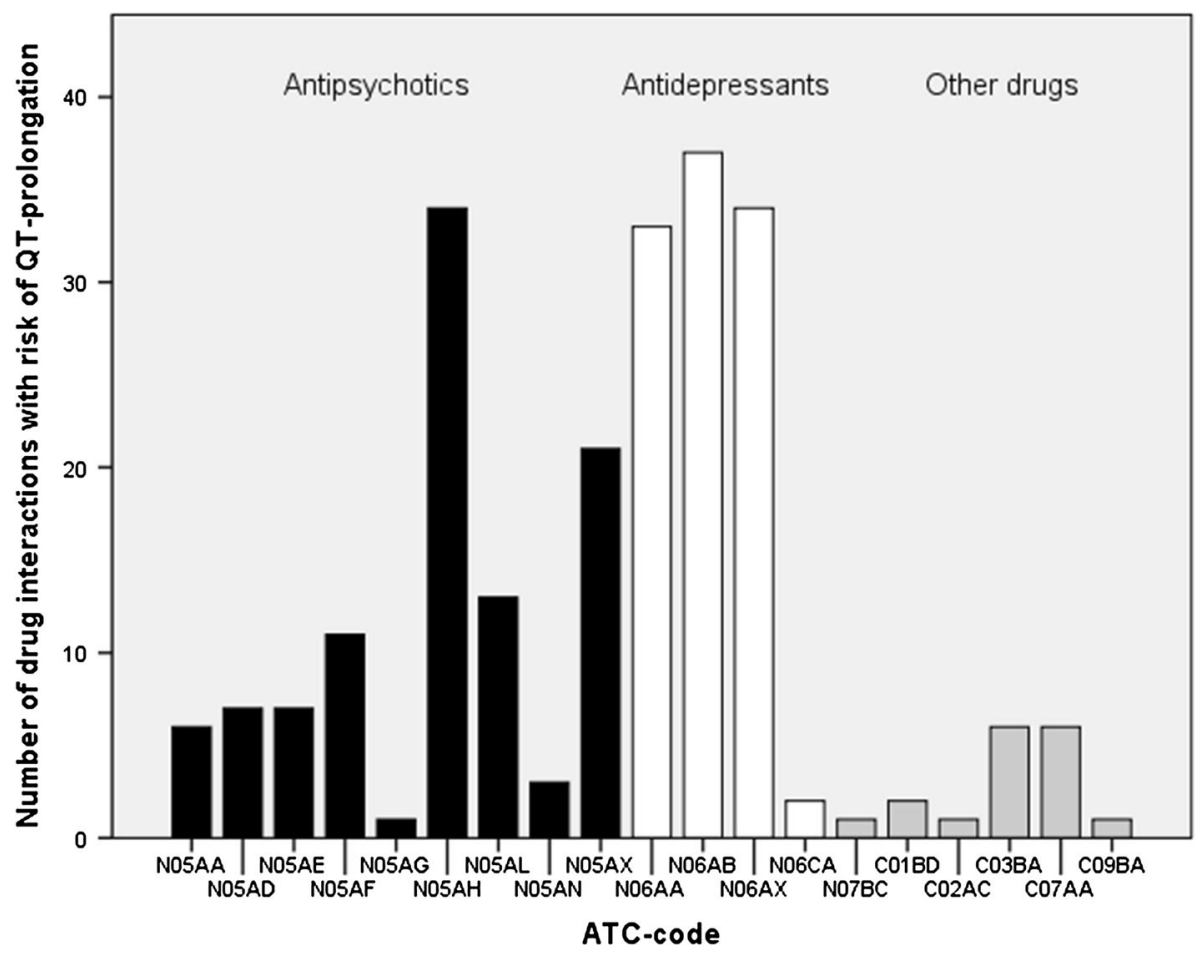

Fig. 1 Drugs involved in the QT-prolonging interactions (drugs are coded in accordance with the ATC-index of the WHO [28]). Antipsychotics N05AA = phenothiazines; N05AD = butyrophenones; $\quad \mathrm{N} 05 \mathrm{AE}=$ indole derivatives; $\mathrm{N} 05 \mathrm{AF}=$ thioxanthenes; $\mathrm{N} 05 \mathrm{AG}=$ difenylpiperidines; $\mathrm{N} 05 \mathrm{AH}=$ diazepines, oxazepines, thiazepines and oxepines; N05AL $=$ benzamides; N05AN = lithium; N05AX $=$ other antipsychotics. Antidepressants N06AA $=$ Non-

Table 3 Antipsychotics and antidepressants that were most involved in drug interactions with risk of QT-prolongation (drugs are coded in accordance with the ATC-index of the WHO [28])

\begin{tabular}{llll}
\hline Antipsychotics (ATC) & $\begin{array}{l}\text { Number of } \\
\text { cases }\end{array}$ & Antidepressants (ATC) & $\begin{array}{l}\text { Number } \\
\text { of cases }\end{array}$ \\
\hline Risperidone (N05AX) & 15 & Venlafaxine (N06AX) & 15 \\
Olanzapine (N05AH) & 14 & Dosulepine (N06AA) & 11 \\
Quetiapine (N05AH) & 14 & Amitriptyline (N06AA) & 11 \\
\hline
\end{tabular}

in pharmacotherapy. Other risk factors besides electrolyte disturbances and baseline QT interval (e.g. history of cardiovascular disease, familial history of SCD, renal function) were not systematically documented in the patient files of the participating institutions.

\section{Discussion}

Frequent use and combination of QT-prolonging drugs

Only a few studies investigated the prevalence of QTprolonging drug use in clinical practice. In 2003, Curtis selective monoamine reuptake inhibitors; $\mathrm{N} 06 \mathrm{AB}=$ selective serotonin reuptake inhibitors; N06AX $=$ other antidepressants; N06CA $=$ antidepressants in combination with psycholeptics. Other drugs $\mathrm{N} 07 \mathrm{BC}=$ Drugs used in opioid dependence; $\mathrm{C01BD}=$ antiarrhythmics, class III; $\mathrm{C} 02 \mathrm{AC}=$ imidazoline receptor agonists; $\mathrm{C} 03 \mathrm{BA}=$ Diuretics, sulfonamides; $\mathrm{C} 07 \mathrm{AA}=$ non-selective beta blocking agents; $\mathrm{C} 09 \mathrm{BA}=\mathrm{ACE}$ inhibitors and diuretics

Table 4 Combinations that most occurred in drug interactions with risk of QT-prolongation

\begin{tabular}{ll}
\hline Combinations & Number of cases \\
\hline Antipsychotic-antidepressant & 64 \\
Antipsychotic-antipsychotic & 14 \\
Antidepressant-antidepressant & 13 \\
Antipsychotic-sotalol & 5 \\
Antipsychotic-indapamide & 3 \\
Antidepressant-indapamide & 3 \\
Antidepressant-lithium & 2 \\
Antipsychotic-lithium & 1 \\
Antidepressant-sotalol & 1 \\
\hline
\end{tabular}

et al. [29] (USA) conducted a retrospective cohort study on the prescription of QT-prolonging drugs using an outpatient prescription claims database (4.8 million patients): 1.1 million patients $(22.8 \%)$ filled prescriptions for at least one QT-prolonging drug and in this population, $9.4 \%$ filled an overlapping prescription for another QT-prolonging drug or a drug that prolongs the clearance of the first drug. Our study differs on several points with this analysis. Firstly, we focused on psychiatric inpatients instead of a 
Table 5 Comparison of the drugs that were involved in the drug interactions with risk of QT-prolongation (DI-QT) identified by DelphiCare (version 2008), with the QT-drug lists of AZCERT (version December 2013) [9]

\begin{tabular}{|c|c|c|c|}
\hline & $\begin{array}{l}\text { Number of } \\
\text { cases }(\%)\end{array}$ & $\begin{array}{l}\text { AZCERT } \\
\text { classification }^{\mathrm{a}}\end{array}$ & $\begin{array}{l}\text { Number of } \\
\text { cases }(\%)\end{array}$ \\
\hline \multicolumn{4}{|c|}{$\begin{array}{l}\text { Drugs involved in DI-QT, classified as very severe by DelphiCare } \\
(\mathrm{n}=26)\end{array}$} \\
\hline \multirow[t]{4}{*}{ Antipsychotics } & $14(53.8)$ & List 1 & $1(7.1)$ \\
\hline & & List 2 & $9(64.3)$ \\
\hline & & List 3 & $2(14.3)$ \\
\hline & & Not in lists & $2(14.3)$ \\
\hline \multirow[t]{4}{*}{ Antidepressants } & $9(34.6)$ & List 1 & 0 \\
\hline & & List 2 & $3(33.3)$ \\
\hline & & List 3 & $5(55.6)$ \\
\hline & & Not in lists & $1(11.1)$ \\
\hline \multirow[t]{4}{*}{ Other drugs } & $3(11.5)$ & List 1 & $3(100.0)$ \\
\hline & & List 2 & 0 \\
\hline & & List 3 & 0 \\
\hline & & Not in lists & 0 \\
\hline \multicolumn{4}{|c|}{$\begin{array}{l}\text { Drugs involved in DI-QT, classified as severe by DelphiCare } \\
(\mathrm{n}=200)\end{array}$} \\
\hline \multirow[t]{4}{*}{ Antipsychotics } & 89 (44.5) & List 1 & 7 (7.9) \\
\hline & & List 2 & $50(56.2)$ \\
\hline & & List 3 & $9(10.1)$ \\
\hline & & Not in lists & $23(25.8)$ \\
\hline \multirow[t]{4}{*}{ Antidepressants } & 97 (48.5) & List 1 & $5(5.2)$ \\
\hline & & List 2 & $28(28.9)$ \\
\hline & & List 3 & $46(47.4)$ \\
\hline & & Not in lists & $18(18.6)$ \\
\hline \multirow[t]{4}{*}{ Other drugs } & $14(7.0)$ & List 1 & $6(42.9)$ \\
\hline & & List 2 & $7(50.0)$ \\
\hline & & List 3 & 0 \\
\hline & & Not in lists & $1(7.1)$ \\
\hline
\end{tabular}

${ }^{\mathrm{a}}$ List $1=$ risk of $\mathrm{TdP}$, list $2=$ possible risk of TdP, list $3=$ conditional risk of $\mathrm{TdP}$

general population. Moreover, we only checked for pharmacodynamic drug interactions with risk of QT-prolongation and not for pharmacokinetic interactions. In our (highrisk) population, QT-prolonging drug interactions were identified in $7.3 \%$ of patients, as compared with $2.2 \%$ in the study from Curtis et al.

Haueis et al. [30] published a comparable analysis in the psychiatric population. They developed an interface for mass analysis of data from the Clinical Decision Support Software MediQ and applied it to prescriptions from 84,607 psychiatric inpatients, collected in five countries (Germany $(74.8 \%), \quad$ Switzerland $(17.9 \%)$, Austria $(6.4 \%)$, Belgium $(0.6 \%)$ and Hungary $(0.3 \%))$. The analysis, partly based on operational classification of drug interactions (ORCA), revealed 387,922 drug interactions
(0.6\% high-danger and $18.3 \%$ average-danger) in $79 \%$ of the patients. Antipsychotics $(40.3 \%)$ and antidepressants $(15.4 \%)$ were most frequently associated with highdanger interactions. More than half of the high-danger interactions resulted in an increased risk of QT-prolongation. There were no results available for the separate countries, so comparison of our results with the data of Belgium in the study of Haueis et al. [30] was not possible. In our study, 965 interactions were identified $(61.5 \%$ severe and $2.2 \%$ very severe) in $60.8 \%$ of patients. All QT-prolonging drug interactions were classified as severe or very severe. QT-prolonging interactions occurred most frequently with antidepressants $(90.27 \%)$ and antipsychotics $(88.50 \%)$. Overall, fewer patients were affected than reported by Haueis et al., but there was a higher number of severe or high-danger drug interactions. These differences might be explained by the different classification systems that were used. Lack of consistency in the classification and information provided by different drug interaction sources can lead to uncertainty among health care professionals on how to handle the interactions, a problem that was mentioned before in several studies [3133].

In our study, we compared the drugs that were involved in the drug interactions with risk of QT-prolongation identified by DelphiCare with the QT-drug lists of AZCERT [9]. In $19.9 \%$ of the cases, the drugs involved in these interactions were not classified in the QT-drug lists of AZCERT. This can be due to different availability of drugs in Belgium and in USA.

Current management of QT-prolonging drugs in clinical practice

We also assessed the precautions and follow-up provided by the different institutions to prevent QT-prolongation and VA. The extent of the use of safety measures was very diverse. None of the six participated psychiatric institutions systematically performed an ECG after starting a QT-prolonging drug in a patient who already took a drug with risk of QT-prolongation. Other risk factors of the patients (besides lab results or baseline QT-interval) were not systematically documented. The lack of systematic risk management regarding QT-prolongation is in sharp contrast with the strict risk management strategies that are implemented for e.g. clozapine induced agranulocytosis and for lithium induced nephropathy. This highlights the urgent need for clear protocols to manage these drug interactions in a safe way. The available international guidelines [5, 24, 25 ] are not implemented in clinical practice and there is no Belgian guideline.

We did not find a difference in the average number of drug interactions per patient between hospitals where 
DelphiCare was integrated in the medical and pharmaceutical and hospitals without a drug interaction checker integrated in the software. Previous studies have shown that drug-drug interaction alerts are often overruled by physicians [34, 35]. One of the main reasons is the perceived high number of unimportant messages, and the lack of time [36]. Moreover a recent study has shown that clinicians who overrule high level drug interaction alerts on QT-prolongation rarely conduct an ECG as a safety measure [37]. Overruling drug interaction alerts by pharmacists has also been an issue in several studies [38, 39], but not specific for drug interactions with risk of QT-prolongation.

\section{Challenges for the future}

There is a clinical dilemma between the need for adequate treatment of mental disorders and the need to minimize the risk of QT-prolongation/TdP and other adverse effects (e.g. the controversy about the regulatory approaches to restrict the use of citalopram [40]). Clinicians should take into account the risk-benefit ratio of the drug they want to prescribe [41]. When it is necessary to prescribe a QTprolonging drug, safety measures should be taken to follow up the risk.

In this study, we observed that QT-prolonging drugs are often combined in psychiatry and adequate safety measures are not systematically used in clinical practice, despite available international guidelines [5, 24, 25]. This highlights the need for QT-studies conducted in clinical practice, with attention to the individual risk factors of the patients (e.g. baseline QT-prolongation, female sex, electrolyte disturbances, history of cardiac arrhythmia or other cardiovascular disease). The results of these studies combined with Continuing Medical Education efforts can lead to an increased awareness of the risk of QT-prolongation and $\mathrm{TdP}$, and initiatives to improve current practice.

Finally, more specific and practical guidelines, that take into account the individual risk factors of the patient as well as lab results, are necessary to help healthcare professionals in the management of QT-prolongation in a responsible way. This approach could lead to better targeted alerts by intelligent software combining multiple data sources, as has been proposed in the literature as an important measure to enhance the acceptance rates of drug interaction alerts [36].

\section{Limitations}

We performed a cross-sectional analysis of data from 592 patients from 6 psychiatric institutions. Most interactions occurred with antipsychotics and antidepressants. We acknowledge the fact that it is difficult to extend our results to general hospitals or to primary care medicine, in which
QT-prolonging interactions probably involve other medication classes (e.g. antibiotics, antifungal agents). This should be the subject of further study.

Secondly, we only checked for pharmacodynamic drug interactions with risk of QT-prolongation and did not take into account the pharmacokinetic interactions. Our results may therefore underestimate the overall prevalence of QTprolonging drug interactions.

The results were obtained in 2008. The precautions and follow-up of QT-prolongation in the involved psychiatric institutions may have been improved since 2008. Moreover, the prescribing behavior and formularies may also have changed since 2008. However, we believe that our message and discussion are still valid.

Finally, we realize that QT-prolongation is an imperfect biomarker of arrhythmic risk. The concept of repolarization reserve limits its sensitivity for the identification of drugs with pro-arrhythmic potential [1, 42]. On the other hand, QT-prolongation is still the most used marker of TdP [43]. At the moment there are no other validated indicators available to measure the risk of VA and sudden cardiac death in psychiatry.

\section{Conclusion}

Drug combinations associated with increased risk of QTprolongation are frequently used in psychiatry. The safety measures that are used to prevent QT-prolongation and $\mathrm{TdP}$, are very diverse in different hospitals. More QTstudies in clinical practice are necessary and persistent efforts should be undertaken to provide caregivers with clear and practical guidelines on how to use these drugs in a responsible and safe way.

Acknowledgments We would like to thank Delphine Lesage, Tinne Leyssens, Eline Sol, Nathalie Rahier, Pieter Ramaut, Annelies Van Huynegem and Hakima Abasbassi from the department of Pharmaceutical Sciences for their contribution to the data collection and analysis. We also want to thank the pharmacists of the 6 psychiatric institutions for their participation: Johan Reyntens, Sint-Jan hospital; Marc De Vos, Sint-Jan-Baptist hospital; Daniel Vrijders, Zoete Nood Gods hospital, Maria De Voght, Sint-Alexius hospital; Erik Pauwels, Sint-Lucia hospital, and Willy De Boever, Sint-Hieronymus hospital.

Funding This work was supported by unconditional grants from Boston Scientific and Medtronic Belgium. Dr. Willems is supported as a clinical researcher by the Fund for Scientific Research Flanders. PhDstudent Eline Vandael is supported by funding of the Belgian government agency for Innovation by Science and Technology (IWT).

Conflicts of interest None.

\section{References}

1. Josephson M, Wellens HJ. Implantable defibrillators and sudden cardiac death. Circulation. 2004;109:2685-91. 
2. Myerburg RJ, Kessler KM, Castellanos A. Sudden cardiac death: epidemiology, transient risk, and intervention assessment. Ann Intern Med. 1993;119:1187-97.

3. Myerburg RJ, Interian A Jr, Mitrani RM, Kessler KM, Castellanos A. Frequency of sudden cardiac death and profiles of risk. Am J Cardiol. 1997;80:10F-9F.

4. van Noord C, Eijgelsheim M, Stricker BH. Drug- and non-drugassociated QT interval prolongation. $\mathrm{Br} \mathrm{J}$ Clin Pharmacol. 2010;70:16-23.

5. Drew BJ, Ackerman MJ, Funk M, Gibler WB, Kligfield P, Menon V, et al. Prevention of Torsade de pointes in hospital settings: a scientific statement from the American Heart Association and the American College of Cardiology Foundation. J Am Coll Cardiol. 2010;55:934-47.

6. Roden DM. Drug-induced prolongation of the QT interval. N Engl J Med. 2004;350:1013-22.

7. U.S. Department of Health and Human Services. Guidance for industry: E14 clinical evaluation of QT/QTc interval prolongation and proarrhythmic potential for non-antiarrhythmic drugs. 2005.

8. Davey P. How to correct the QT interval for the effects of heart rate in clinical studies. $\mathrm{J}$ Pharmacol Toxicol Methods. 2002;48:3-9.

9. Arizona Center for Education and Research on Therapeutics (AZCERT): QT drug lists by risk groups. 2013. http://www.cre diblemeds.org (last accessed 19 Dec 2013) (online).

10. De Bruin ML, Pettersson M, Meyboom RH, Hoes AW, Leufkens HG. Anti-HERG activity and the risk of drug-induced arrhythmias and sudden death. Eur Heart J. 2005;26:590-7.

11. Straus SM, Sturkenboom MC, Bleumink GS, Dieleman JP, van der Lei J, de Graeff PA, et al. Non-cardiac QTc-prolonging drugs and the risk of sudden cardiac death. Eur Heart J. 2005;26:2007-12.

12. Armahizer MJ, Seybert AL, Smithburger PL, Kane-Gill SL. Drug-drug interactions contributing to QT prolongation in cardiac intensive care units. J Crit Care. 2013;28:243-9.

13. Jolly K, Gammage MD, Cheng KK, Bradburn P, Banting MV, Langman MJ. Sudden death in patients receiving drugs tending to prolong the QT interval. Br J Clin Pharmacol. 2009;68:743-51.

14. Ray WA, Chung CP, Murray KT, Hall K, Stein CM. Atypical antipsychotic drugs and the risk of sudden cardiac death. N Engl J Med. 2009;360:225-35.

15. Leonard CE, Freeman CP, Newcomb CW, Bilker WB, Kimmel SE, Strom BL, et al. Antipsychotics and the risks of sudden cardiac death and all-cause death: cohort studies in medicaid and dually-eligible medicaid-medicare beneficiaries of five states. J Clin Exp Cardiol. 2013;10:1-9.

16. Beach SR, Celano CM, Noseworthy PA, Januzzi JL, Huffman JC. QTc prolongation, Torsades de Pointes, and psychotropic medications. Psychosomatics. 2013;54:1-13.

17. Castro VM, Clements CC, Murphy SN, Gainer VS, Fava M, Weilburg JB, et al. QT interval and antidepressant use: a cross sectional study of electronic health records. BMJ. 2013;346:288.

18. Leonard CE, Bilker WB, Newcomb C, Kimmel SE, Hennessy S. Antidepressants and the risk of sudden cardiac death and ventricular arrhythmia. Pharmacoepidemiol Drug Saf. 2011;20:903913.

19. Moller HJ, Seemuller F, Schennach-Wolff R, Stubner S, Ruther E, Grohmann R. History, background, concepts and current use of comedication and polypharmacy in psychiatry. Int J Neuropsychopharmacol. 2013;18:1-14.

20. Seemuller F, Riedel M, Obermeier M, Bauer M, Adli M, Kronmuller $\mathrm{K}$, et al. Outcomes of 1014 naturalistically treated inpatients with major depressive episode. Eur Neuropsychopharmacol. 2010;20: 346-55.

21. Stubner S, Grohmann R, von SI, Ruther E, Moller HJ, MullerOerlinghausen B, et al. Suicidality as rare adverse event of antidepressant medication: report from the AMSP multicenter drug safety surveillance project. J Clin Psychiatry. 2010;71:1293-307.

22. Patel MX, Bishara D, Jayakumar S, Zalewska K, Shiers D, Crawford MJ, et al. Quality of prescribing for schizophrenia: evidence from a national audit in England and Wales. Eur Neuropsychopharmacol. 2014;24:499-509.

23. Sala M, Vicentini A, Brambilla P, Montomoli C, Jogia JR, Caverzasi E, et al. QT interval prolongation related to psychoactive drug treatment: a comparison of monotherapy versus polytherapy. Ann Gen Psychiatry. 2005;4:1.

24. Barnes T, Davison S, Ferrier IN, Howard R, Kerwin R, King DJ, et al. Consensus statement on high-dose antipsychotic medication. London: Royal College of Psychiatrists. 2005.

25. Ames D, Camm J, Cook P, Falkai P, Gury C, Hurley R, et al. Minimizing the risks associated with QTc prolongation in people with schizophrenia. A consensus statement by the Cardiac Safety in Schizophrenia Group. Encephale. 2002;28:552-62.

26. Ozeki Y, Fujii K, Kurimoto N, Yamada N, Okawa M, Aoki T, et al. QTc prolongation and antipsychotic medications in a sample of 1017 patients with schizophrenia. Prog Neuropsychopharmacol Biol Psychiatry. 2010;34:401-5.

27. Reilly JG, Ayis SA, Ferrier IN, Jones SJ, Thomas SH. QTcinterval abnormalities and psychotropic drug therapy in psychiatric patients. Lancet. 2000;355:1048-52.

28. WHO Collaborating Centre for Drug Statistics Methodology. ATC/DDD index. 2013. http://www.whocc.no/atc_ddd_index (last accessed 15 Apr 2014) (online).

29. Curtis LH, Ostbye T, Sendersky V, Hutchison S, Allen LaPointe NM, Al-Khatib SM, et al. Prescription of QT-prolonging drugs in a cohort of about 5 million outpatients. Am J Med. 2003;114:135-41.

30. Haueis P, Greil W, Huber M, Grohmann R, Kullak-Ublick GA, Russmann S. Evaluation of drug interactions in a large sample of psychiatric inpatients: a data interface for mass analysis with clinical decision support software. Clin Pharmacol Ther. 2011;90:588-96.

31. Abarca J, Malone DC, Armstrong EP, Grizzle AJ, Hansten PD, Van Bergen $\mathrm{RC}$, et al. Concordance of severity ratings provided in four drug interaction compendia. $\mathrm{J}$ Am Pharm Assoc. 2004;44:136-41.

32. Vitry AI. Comparative assessment of four drug interaction compendia. Br J Clin Pharmacol. 2007;63:709-14.

33. Wong CM, Ko Y, Chan A. Clinically significant drug-drug interactions between oral anticancer agents and nonanticancer agents: profiling and comparison of two drug compendia. Ann Pharmacother. 2008;42:1737-48.

34. Isaac T, Weissman JS, Davis RB, Massagli M, Cyrulik A, Sands DZ, et al. Overrides of medication alerts in ambulatory care. Arch Intern Med. 2009;169:305-11.

35. Weingart SN, Toth M, Sands DZ, Aronson MD, Davis RB, Phillips RS. Physicians' decisions to override computerized drug alerts in primary care. Arch Intern Med. 2003;163:2625-31.

36. Kuperman GJ, Bobb A, Payne TH, Avery AJ, Gandhi TK, Burns $\mathrm{G}$, et al. Medication-related clinical decision support in computerized provider order entry systems: a review. J Am Med Inform Assoc. 2007;14:29-40.

37. van der Sijs H, Kowlesar R, Klootwijk AP, Nelwan SP, Vulto AG, van GT. Clinically relevant QTc prolongation due to overridden drug-drug interaction alerts: a retrospective cohort study. Br J Clin Pharmacol. 2009;67:347-54.

38. Indermitte J, Beutler M, Bruppacher R, Meier CR, Hersberger KE. Management of drug-interaction alerts in community pharmacies. J Clin Pharm Ther. 2007;32:133-42.

39. Murphy JE, Forrey RA, Desiraju U. Community pharmacists' responses to drug-drug interaction alerts. Am J Health Syst Pharm. 2004;61:1484-7.

40. Zivin K, Pfeiffer PN, Bohnert AS, Ganoczy D, Blow FC, Nallamothu BK, et al. Evaluation of the FDA warning against 
prescribing citalopram at doses exceeding $40 \mathrm{mg}$. Am J Psychiatry. 2013;170:642-50.

41. Narang P, El-Refai M, Parlapalli R, Danilov L, Manda S, Kaur G, et al. Antipsychotic drugs: sudden cardiac death among elderly patients. Psychiatry (Edgmont). 2010;7:25-9.

42. Drezner JA, Ackerman MJ, Cannon BC, Corrado D, Heidbuchel $\mathrm{H}$, Prutkin JM, et al. Abnormal electrocardiographic findings in athletes: recognising changes suggestive of primary electrical disease. Br J Sports Med. 2013;47:153-67.

43. Nielsen J, Graff C, Kanters JK, Toft E, Taylor D, Meyer JM. Assessing QT interval prolongation and its associated risks with antipsychotics. CNS Drugs. 2011;25:473-90. 